\title{
Evaluation of High Land Sorghum (Sorghum bicolor L. Meonch) Varieties for Yield Performance
}

\author{
Zigale Semahegn ${ }^{1}$, Temesgen Teressa ${ }^{1}$, Zewdu Asrat $^{1}$, Temesgen Begna ${ }^{1}$, Workissa Yali ${ }^{1}$, Hailu Gichele ${ }^{1}$, \\ Moges Mekonnen ${ }^{1}$, Abdulfeta Tariku ${ }^{1}$, Tamirat Bejiga ${ }^{2}$ \\ 1.Ethiopian Institute of Agricultural Research, Chiro National Sorghum Research and Training Center \\ 2. Ethiopian Institute of Agricultural Research, Melkassa Agricultural Research Center
}

\begin{abstract}
Despite of biotic and abiotic stress, the yield performance of crop varieties is affected by environment and Genotype by Environment interaction, which is the major challenge to plant breeders while developing improved varieties. In Ethiopia, high yielding, and stable varieties that withstand disease in the highland areas are limited. In view of this, the yield performance of nine sorghum varieties and one standard check were tested at three environments with the objectives of identifying the best performing and adapting varieties across environments. The experiment was conducted using Randomized Complete Block Design with Row Column arrangement and three replications. The combined analysis of variance across environments showed highly significant $(\mathrm{P}<0.001)$ difference among environments, genotypes and interactions for grain yield, days to flowering and plant height studied. Based on generalized linear model showed that variety Jiru, and variety Chiro and variety Dibaba were the high yielders, while variety Fendisha-1 and Variety Muyra-2 were the lower ones. From farmers' point of view, during evaluation based on their traits of interest (yield, plant biomass, head compactness, seed size, and seed color) variety Jiru was superior yield and adaptable, and therefore, recommended in the study areas. Generally, this study revealed the importance of evaluating released sorghum varieties for their yield and adaptability across diverse highland areas of Ethiopia.
\end{abstract}

Keywords: Sorghum, Analysis of Variance, Genotype by environment interaction

DOI: $10.7176 / \mathrm{JNSR} / 11-23-03$

Publication date: December $31^{\text {st }} 2020$

\section{INTRODUCTION}

Sorghum is the fifth most important cereal crop in the world (FAOSTAT, 2018). In Ethiopia, it ranks third in area coverage and production, after maize and teff and it is contributing $16.4 \%$ of the total annual cereal grain production (CSA, 2018). Currently sorghum is produced by 6 million holders and its production is estimated to be 5.2 million metric tons from 2.1 million hectares of land giving the national average grain yield of around 2.7 tons per hectare (CSA, 2018). In Ethiopia, sorghum provides food, fodder and alcoholic beverages. The main use of sorghum in Ethiopia is for making Injera. Due to the country is following mixed agricultural system, sorghum biomass has also almost equally importance as grain for animal feed, construction purpose and fuel wood.

However, the current rate of yield increment in sorghum is limited in Ethiopia. Even though, a number of biotic and abiotic factors contributed to the limiting grain yield increment, diseases are considered as one of the major biotic factors limiting sorghum productivity in the highland and intermediate areas of Ethiopia. These limitations are tackled by developing sorghum genotypes, which are more tolerant to leaf and grain diseases (Gebreyohannes et al., 2018). A challenge of sorghum production in the highland and intermediate parts of the country is lack of tolerant sorghum varieties to diseases, striga, stable and adaptable varieties, poor adoption of improved varieties by farmers, due to poor farmers participatory during selection (on-station) and inadequate knowledge of farmers about the varieties. Developing of tolerant varieties that can withstand biotic stress through introgression of resistant trait are the strategies being embedded in the sorghum breeding in Ethiopia.

Many findings have been reported on the performance of sorghum varieties in different agro-ecologies (Kinde et al., 2016; Fantaye and Hintsa, 2017; Amare et al., 2019, Zigale et al., 2019) and they reported the existence of the diverse performance and stability of the sorghum varieties across environments. Yield stability is one of the challenges facing plant breeders in developing broadly adapted with high yielder varieties (Asfaw, 2005). National sorghum research program, higher institutes and regional research centers were released more than sixty sorghum varieties, and from these ten varieties are released for the highland areas of Ethiopia. However, the released highland sorghum varieties were not evaluated and addressed in all highland areas of Ethiopia. Therefore, this study was conducted with the objective of identifying the best performing and adapting varieties across envirnments.

\section{Materials and Methods \\ Description of the study area}

The field experiment was conducted under rainfed conditions during the 2018 and 2019 main cropping season at two locations (Hirna and Alemata)), representing the highland areas of Ethiopia. Hirna station is located at $9^{\circ} 12^{\prime}$ 
$\mathrm{N}$ latitude, $41^{\circ} 4^{\prime} \mathrm{E}$ longitude and at an altitude of $1870 \mathrm{~m}$.a.s.l. The area receives mean annual rainfall ranging from 990 to $1010 \mathrm{~mm}$. The average temperature of the area is $24.0^{\circ} \mathrm{C}$. The soil of Hirna is vertisol (Haramaya University Research Center, 1996).

\section{Genetic materials, experimental design and trial management}

Planting materials (Table 1) used for the experiment consisted of eight sorghum varieties, which were released from national sorghum Research program and Haramaya University and single variety as a standard check. The trial was conducted using Randomized Complete Block Design with row column arrangement and three replications. The experimental plot consisted of 3 rows, each $5 \mathrm{~m}$ in length with $0.75 \mathrm{~m}$ between row spacing. The total area of each plot had a size of $11.25 \mathrm{~m}^{2}$.

As per the recommended rate for Sorghum production in the highland areas of Ethiopia, Both Di-ammonium phosphate (DAP) and urea were applied at the rate of $100 \mathrm{~kg} / \mathrm{ha}$. Diammonium phosphate was applied by incorporating into the soil during planting of the seeds, while urea was applied as side dressing at knee height stage after planting of the seed. Thinning was done after three weeks of planting to maintain the space between plants and to balance the plant density. Other crop management practices were done following the recommended practices. Days to 50\% flowering, plant height (cm), grain yield per plot (GY) and converted to ha- 1 , days to $90 \%$ physiological maturity (DTM), plant aspect (PAS) data were collected and analyzed to identify stable and superior varieties compared with the standard check variety.

Using the raw data collected on days to flowering, maturity, overall plant aspect, plant height and grain yield of ten varieties, which were grown at two locations, analysis of data using generalized linear model under Genstat 17 th ed. Software was computed; analysis of data using generalized linear model of RCBD with row column arrangement was computed. Before pooling the data over locations, Bartlett's test of homogeneity of variance was done for the traits to determine the validity of the overall analysis of variance of the data of combined locations. This analysis revealed the homogeneity of error variance. Therefore, overall analysis of variance was done to determine the effects of the genotypes, locations and their first order interactions using generalized linear model. Least significance difference was used to determine the significance of differences among the genotype means for days to flowering, maturity, overall plant aspect, plant height and grain yield.

Table 1: Description of sorghum genotypes tested at five two during 2018 and 2019 main cropping season

\begin{tabular}{cccc}
\hline Entry & Genotype & Year of released & Breeder/Maintainer \\
\hline 1 & Adelle & 2016 & Melkassa \\
2 & Jiru & 2016 & Melkassa \\
3 & Dibaba & 2015 & Melkassa \\
4 & Chiro & 1996 & Melkassa \\
5 & Chelenko & 2005 & Melkassa \\
6 & ETS2752 & - & Melkassa \\
7 & AL-70 & - & Melkassa \\
8 & Fendisha-1 & 2015 & Haramaya University \\
9 & Muyra-1 & 2000 & Haramaya University \\
10 & Muyra-2 & 2000 &
\end{tabular}

\section{RESULTS AND DISCUSSIONS}

The combined analysis of variance by generalized linear model of days to flowering, maturity, overall plant aspect, plant height and grain yield for ten varieties is presented in table 2 . The result revealed that there were very highly significant $(\mathrm{p} \leq 0.0001)$ differences among sites, genotypes and interactions for grain yield, days to flowering and plant height (Table 2). This indicates that the high diversity of the growing conditions in the three environments and large variability in the varieties for grain yield, days to flowering and plant height. The very highly significant for Genotype by Environment Interaction is also showing inconsistencies in the performance of sorghum varieties across environments which show difference in the response of sorghum varieties at different environments. It means a breeder faces challenge of selection varieties for advancement, hence further evaluating of varieties with wider and specific adaptation and environments with good discriminating ability and representativeness is needed for further investigation. This result (especially for grain yield) is in agreement with the finding of Abiy and Firew (2016); Asfaw (2007); Zigale et al. (2019); Amare et al. (2019); Worede et al. (2020) observed significance difference of genotype, environment and genotype by environment interaction for days to flowering, plant height and grain yield. However, the result showed that there were only very highly significant differences among genotypes and interactions, while there were significant differences among environments for days to flowering and overall plant aspect. 
Table 2: Analysis of variance of highland sorghum varieties on mean days to flowering, days to maturity, plant height, overall plant aspect, grain yield ( $\mathrm{kg} / \mathrm{ha})$ by generalized linear model tested at two locations during 2018 and 2019 main cropping season

\begin{tabular}{l|l|lllll}
\hline \multirow{2}{*}{ Sources of variation } & \multirow{2}{*}{} & \multicolumn{5}{|c}{ Mean square } \\
\cline { 3 - 6 } & DF & GY & DTF & DTM & PHT & PAS \\
\hline Genotype & 9 & $15361265^{* *}$ & $304^{* *}$ & $66.7^{\text {ns }}$ & $1991.6^{* *}$ & $2.6^{* *}$ \\
Environment & 2 & $10400388^{* *}$ & $39936.6^{* *}$ & $1238^{* *}$ & $158986.7^{* *}$ & $2.2^{\text {ns }}$ \\
Genotype:Environment & 18 & $4685081^{* *}$ & $174.1^{* *}$ & $54.4^{\text {ns }}$ & $858.8^{* *}$ & $1.7^{* *}$ \\
Replicate/ Environment & 6 & $932557^{\text {ns }}$ & 13.4 & $21.1^{\text {ns }}$ & $1685^{* *}$ & $0.1^{\text {ns }}$ \\
Error & 53 & 516869 & 68.5 & 48.4 & 352 & 0.5 \\
Total & 88 & 3140603 & 1016.5 & 70.8 & 4275 & 1 \\
\hline
\end{tabular}

\section{Performance of the genotypes}

The mean values of the sorghum varieties for the traits considered are depicted in Table 3. Jiru and Fendisha-1 were the highest and least-yielding varieties with the yield of $5385.3 \mathrm{~kg} / \mathrm{ha}$ and $1535.7 \mathrm{~kg} / \mathrm{ha}$, respectively. This showed the presence of cross over interaction across the testing locations. In general, ranking of varieties changed from one environment to another, indicates that, a remarkable Genotype by Environment and require further study to understand the patterns of interactions. This result is similarly reported by Zigale et al. (2019); Amare et al. (2019); Chalachew and Zigale (2019); Worede et al. (2020). With regards to overall plant aspect, Jiru (2.4) was better comparatively high attributes of seed color, seed size, threshability, panicle shape, disease and insect and lodging tolerance, good biomass.

When the grand mean values of the three environments were compared, 19AL (6823 kg/ha) followed by Chiro (6544 kg/ha) had higher sorghum grain yield, while $19 \mathrm{HN}(1244 \mathrm{~kg} / \mathrm{ha})$ had the smallest sorghum grain yield. Environments 19AL and $19 \mathrm{HN}$ could, therefore, be regarded as the highest and the lowest yielding environments, respectively. Jiru $(6823 \mathrm{~kg} / \mathrm{ha})$ and Muyra-2 $(1244 \mathrm{~kg} / \mathrm{ha})$ were the highest and least yielding varieties on the high and low yielding environments, respectively (Table 3). This result is in agreement with the finding of Zigale et al. (2019); Amare et al. (2019); Chalachew and Zigale (2019); Worede et al. (2020) were reported the highest and least yielding varieties on the high and low yielding environments.

Table 3: Mean grain yield $(\mathrm{kg} / \mathrm{ha})$ of 10 sorghum varieties across three environments.

\begin{tabular}{ll|lll|l}
\hline \multirow{2}{*}{ Entry } & & \multicolumn{3}{|l|}{ Environments } & \\
\cline { 3 - 4 } & Varieties & 19HN & $18 \mathrm{HN}$ & $19 \mathrm{AL}$ & Mean \\
\hline 1 & Adelle & 4326 & 4622 & 2624 & 3857.3 \\
2 & AL-70 & 2930 & 4859 & 2403 & 3397.3 \\
3 & Chelenko & 2444 & 5481 & 2249 & 3391.3 \\
4 & Chiro & 2989 & 4741 & 6544 & 4758 \\
5 & Dibaba & 4128 & 6430 & 1895 & 4151 \\
6 & ETS2752 & 4340 & 4178 & 3611 & 4043 \\
7 & Fendisha-1 & 1391 & 1642 & 1574 & 1535.7 \\
8 & Jiru & 3911 & 5422 & 6823 & 5385.3 \\
9 & Muyra-1 & 1444 & 1481 & 2869 & 1931.3 \\
10 & Muyra-2 & 1244 & 1452 & 2140 & 1612 \\
& Mean & 2915 & 4031 & 3273 & 3406.2 \\
& LSD (0.05) & 260.4 & 1886 & 461 & 869.1 \\
& CV (0.05) & 9.5 & 27.3 & 15 & 17.3 \\
\hline
\end{tabular}

Where, $19 \mathrm{AL}=2019$ Alemata, 19HN = 2019 Hirna, 18HN = 2018 Hirna, LSD $=$ Lease significance difference, $\mathrm{CV}=$ Coefficient of variation 
Table 4: Mean grain yield and other agronomic traits of sorghum varieties evaluated at three environments.

\begin{tabular}{lccccc}
\hline Variety & DTF & DTM & PHT & GY & PAS \\
\hline Jiru & 149.4 & 217.9 & 357.8 & 5385.3 & 2.4 \\
Dibaba & 158.5 & 222.9 & 361.7 & 4151.0 & 2.7 \\
ETS2752 & 150.1 & 212.7 & 346.8 & 4043.0 & 2.8 \\
Adelle & 159.2 & 218.8 & 367.3 & 3857.3 & 2.8 \\
Chiro & 152 & 215.9 & 328.9 & 4758.0 & 3.2 \\
AL-70 & 154.6 & 220 & 336.8 & 3397.3 & 3.7 \\
Fendisha & 163.1 & 225.3 & 355.2 & 1535.7 & 3.7 \\
Chelenko & 154.2 & 217.4 & 345.8 & 3391.3 & 3.9 \\
Muyra-1 & 158 & 219.6 & 320.9 & 1931.3 & 4.0 \\
Muyra-2 & 167.9 & 218.9 & 355.5 & 1612.0 & 4.4 \\
Mean & 155.1375 & 218.8625 & 350.0375 & 3406.2 & 3.2 \\
LSD (0.05) & 7.9 & 8.2 & 17.7 & 869.1 & 0.9 \\
CV (0.05) & 5.3 & 3.2 & 5.4 & 17.3 & 21.1 \\
\hline
\end{tabular}

Where, DTF $=$ Days to flowering, DTM = Days to maturity, PHT $=$ Plant height, GY = Grain yield and PAS $=$ Overall agronomic plant aspect.

\section{CONCLUSION}

The combined analysis of variance showed the studied sorghum varieties were significantly different in most traits measured. The finding of this study showed that Jiru (5385.3 kg/ha), Chiro (4758.0 kg/ha), Dibaba (4151.0 kg/ha) had good yield performance, high plant biomass and very good overall agronomic desirable traits (seed color, head compactness, grain size, shape and thresh ability) over the standard check AL-70, while yields of other varieties reduced due to low yield potential.

Generally, from farmers' preference, during evaluation based on their traits of interest (yield, plant biomass, head compactness, seed size, and seed color) and results obtained from the experiment, it was showed that the present study entails the presence of significant variation in sorghum yield increment. Therefore, the sorghum variety, Jiru was identified as superior for grain yield and adaptable in the study areas.

\section{REFERENCES}

Abiy L, Firew M (2016) Genotype X environment interaction and stability of early maturing sorghum [Sorghum bicolor (L.) Moench] genotypes in Ethiopia. M.Sc. Thesis, Haramaya University of Agriculture, Ethiopia.

Adane Gebreyohannes, Taye Tadesse, Amare Seyoum, Habte Nida, Amare Nega, Tsegau Senbetay and Chalachew Endalemaw (2018). African Journal of Agricultural Research: Vol. 13(49), pp. 2780-2787.DOI: 10.5897/AJAR2018.13481

Asfaw Adugnua (2007). Assessment of Yield Stability in Sorghum, African Crop Science Journal, vol.15, No, 2 pp 83-92.

Central Statistical Agency of Ethiopia (2018) Agricultural Sample Survey 2018.

Fantaye B, Hintsa M (2017) Performance evaluation of sorghum [Sorghum bicolor (L.) Moench] hybrids in the moisture stress conditions of Abergelle District, Northern Ethiopia. J Cereals Oilseeds 8: 26-32.

FAOSTAT (2018). UN Food and Agriculture Organization Statistics [Online]. (accessed April 7, 2018).

Kinde L, Gebeyehu C, Abubeker T, Dadi G, Shanene H, et al. (2016) Evaluation of sorghum (Sorghum bicolor (L) Moench) varieties and environments for yield performance and stability. J Biol Agric Healthcare 6: 21.

Worede F, Mamo M, Assefa S, Gebremariam T and Beze Y (2020). Yield stability and adaptability of lowland sorghum (Sorghum bicolor (L.) Moench) in moisture-deficit areas of Northeast Ethiopia. Cogent Food \& Agriculture (2020), 6: 1736865: https://doi.org/10.1080/23311932.2020.1736865

Yitayeh ZS, Bisetegn KB , Mindaye TT, Bisetegn KB (2019) AMMI and GGE Analysis of GxE and Yield Stability of Early Maturing Sorghum [Sorghum bicolor (L.) Moench] Genotypes in Dry Lowland Areas of Ethiopia. Adv Crop Sci Tech 5: 425. doi: 10.4172/2329 8863.1000425 